\title{
Transparent Conductive Thin Films of Aluminum-doped Zinc Oxide Prepared by Magnetron Sputtering
}

\author{
H. ZHU ${ }^{a, *} ; H$. M. WANG ${ }^{a}$; S. Q. GONG ${ }^{a} ; H$. Y. KUANG ${ }^{b}, Y . X$. WANG $^{c}$ \\ ${ }^{a}$ Department of Mechanical and Electrical Engineering, Jingdezhen Ceramic Institute, Jingdezhen, \\ Jiangxi 333001, PR China \\ ${ }^{\mathrm{b}}$ Technology and Arts of Jingdezhen Ceramic Institute, Jingdezhen, Jiangxi 333001, PR China \\ ${ }^{c}$ Department of Materials Science and Engineering, Jingdezhen Ceramic Institute, Jingdezhen, \\ Jiangxi 333001, PR China
}

*Corresponding author:zwchua@163.com

Keywords: Aluminum-doped zinc oxide; Magnetron sputtering; Substrate temperature; X-ray diffraction; Transmittance; Resistivity

\begin{abstract}
Transparent conductive thin films of aluminum-doped zinc oxide (ZAO) were prepared by radio-frequency magnetron sputtering with $\mathrm{ZAO}\left(98 \mathrm{wt} \% \mathrm{ZnO}, 2 \mathrm{wt} \% \mathrm{Al}_{2} \mathrm{O}_{3}\right.$ ) as the ceramic target. The visible transmittance was investigated by ultraviolet-visible spectroscopy, the carrier concentration and Hall mobility were measured by the Van der Pauw method, and the phase composition was characterized by X-ray diffraction. The results show that the substrate temperature was a dominant factor of the properties, with the $\mathrm{ZnO}$ film deposited at a substrate temperature of $200{ }^{\circ} \mathrm{C}$ and a pure-argon gas pressure of $1 \mathrm{~Pa}$ exhibiting optimal performance. The resistivity and average transmittance in the wavelength range of 300-760 nm were $2.0 \times 10^{-4} \Omega \mathrm{cm}$ and $90.6 \%$, respectively.
\end{abstract}

\section{Introduction}

Aluminum-doped zinc oxide (ZAO) films are especially attractive materials among different oxide materials because of the abundance of raw materials, low cost, environmental friendliness, and stability in hydrogen plasma. The effects of the substrate temperature on the properties of $\mathrm{ZnO}$ thin films have been reported by many research groups ${ }^{[1-3]}$. ZAO film's quality and its photoelectric performance are affected by process parameters such as substrate temperature ${ }^{[4]}$, sputtering time ${ }^{[5]}$, sputtering power ${ }^{[6]}$, target-substrate distance, working pressure ${ }^{[7]}$, annealing temperature and annealing time ${ }^{[4,8]}$. B.L.Zhu et al ${ }^{[9]}$ discovered that $\mathrm{ZnO}$ films grown at room temperature suffer compressive stress and the tensile stress exists in films grown at a substrate temperature of 200-500 ${ }^{\circ} \mathrm{C}$. Zhiyun Zhang et $\mathrm{al}^{[10]}$ discovered that all the films deposited at different substrate temperature from RT to $350^{\circ} \mathrm{C}$ exhibited residual tensile strain. In our study, ZAO thin films were deposited on glass substrates by RF magnetron sputtering, with the substrate temperature ranging from room temperature (RT) to $300{ }^{\circ} \mathrm{C}$. The crystalline, microstructure, optical and electrical properties of the films were investigated.

\section{Experimental procedures}

ZAO thin films were deposited by a radio-frequency (RF) magnetron sputtering system (JSD-300, JS Vacuum, China). The ceramic ZnO: Al2O3 (2 wt \%) was $50 \mathrm{~mm}$ in diameter and 99.99\% in purity. Soda-lime glass sheets were used as the substrates cleaned successively in an ultrasonic bath with acetone, alcohol and deionized water for $10 \mathrm{~min}$ before being loaded into the chamber. The target-base distance is $60 \mathrm{~mm}$. The base pressure of the chamber was kept at $6 \times 10^{-4} \mathrm{~Pa}$. Pure $\mathrm{Ar}$ gas was supplied into the sputtering chamber maintained at $1 \mathrm{~Pa}$ in pressure at $100 \mathrm{~W}$ 's sputtering power. The substrate temperatures $(S T)$ was set at $25,100,200$ and $300{ }^{\circ} \mathrm{C}$, respectively, and samples were obtained and rapidly cooled to RT in air. An X-ray diffractometer (XRD; D8 Advance, Bruker AXS, Germany) with $\mathrm{Cu} K_{\alpha}$ as the radiation source was used to identify the film's 
phase composition. The film's surface was observed by a cold-field-emission scanning electron microscope (JSM-6700F, JEOL, and Japan) operated at $5 \mathrm{kV}$. The electrical properties of the films were measured using the van der Pauw method at room temperature with Hall Effect measurement system (HMS3000, Ecopia, Korea).

\section{Results and discussion}

\section{Structural characterization}

Fig.1 shows XRD diffraction patterns of the ZAO films deposited at different substrate temperatures. Weak (002) peak and a stronger (100) peak were emerged at $S T=25^{\circ} \mathrm{C}$. When $S T$ was raised to $100{ }^{\circ} \mathrm{C}$, the (002) peak became stronger. As $S T$ was further increased to 200 and $300^{\circ} \mathrm{C}$, only (002) dpeak was observed in the deposited film, indicating that the atoms had sufficient energy to settle in stable positions and had the tendency to adopt the orientation of the (002) plane to minimize the surface energy at higher $S T$. The (100) peak deposited at $S T<100{ }^{\circ} \mathrm{C}$ in ZAO films indicating that the number of crystals oriented along the $c$-axis decreased. In addition, it was also observed that no $\mathrm{Al}_{2} \mathrm{O}_{3}$ phase was present, which implies that most of the $\mathrm{Al}$ atoms were in substitutions for $\mathrm{Zn}$ atoms in the $\mathrm{ZnO}$ lattice or $\mathrm{Al}$ interstitial atoms between the lattices.

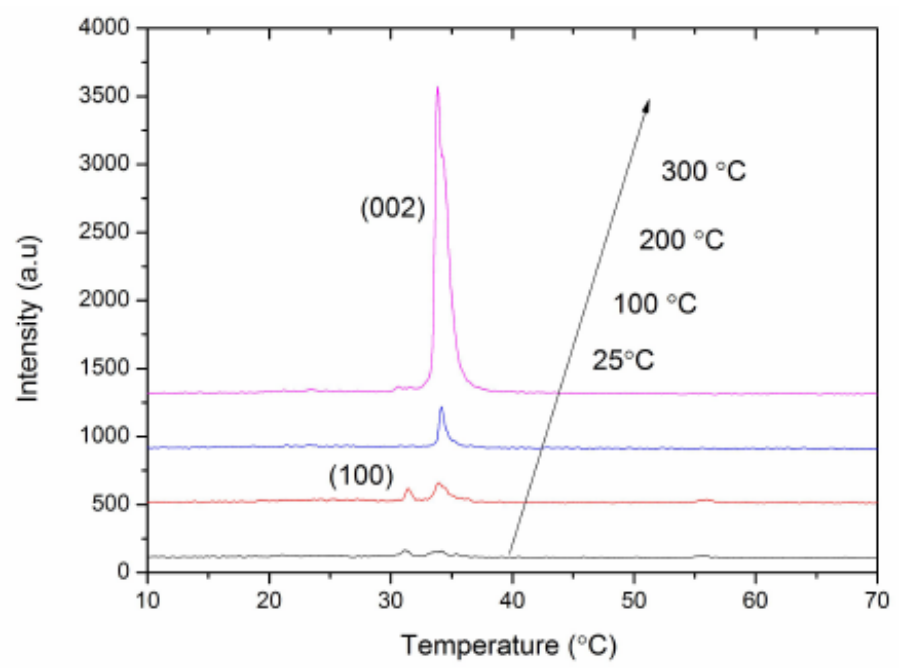

Figure 1 XRD diffraction curves of samples at different substrate temperature

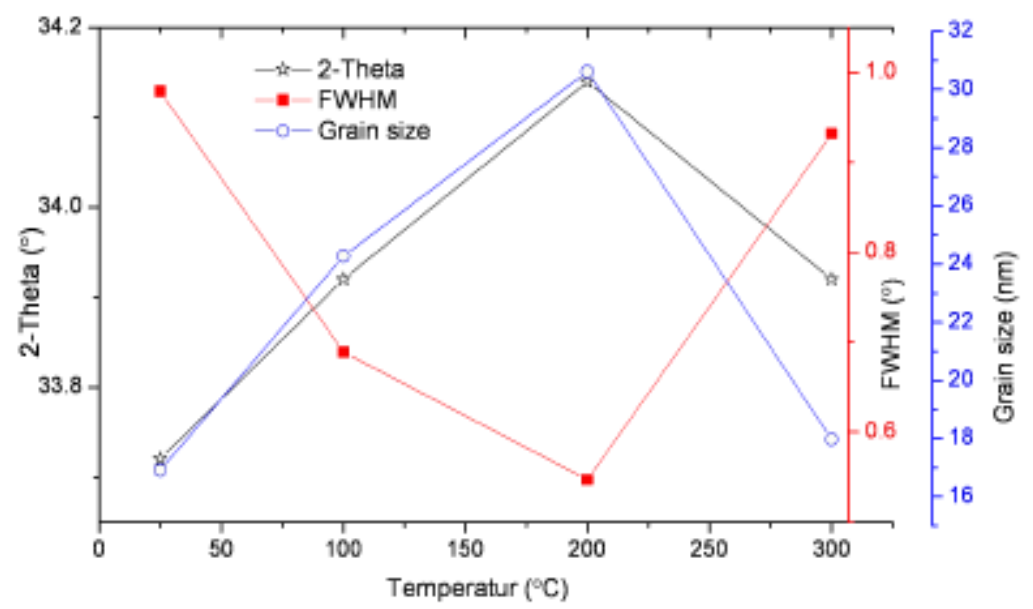

Figure 2 Theta, FWHM, and grain size of the samples

Variations of $2 \theta$, full width at half maximum (FWHM), and the grain size of the (002) diffraction peak were also investigated, as shown in Fig.2. When ST increased from 25 to $200{ }^{\circ} \mathrm{C}, \mathrm{FWHM}$ decreased and the peak position of (002) gradually moved from 33.72 to $34.14^{\circ}$, particularly, 
FWHM decreased sharply with ST increasing from 100 to $200{ }^{\circ} \mathrm{C}$. Then when ST increased from 200 to $300^{\circ} \mathrm{C}$, FWHM increased and the position of the (002) diffraction peak slightly decreased from 34.14 to $33.92^{\circ}$. Compared $2 \theta$ of $34.42^{\circ}$ for the (002) diffraction peak to bulk $\mathrm{ZnO}$, the decrease in the diffraction peak angle corresponds to an increase in the interplanar spacing of (002), indicating that there was compressive stress in the ZAO thin films. The reason is that the prepared films were rapidly cooled to room temperature and substrate shrinks faster than the film, because the thermal expansion coefficient of $\mathrm{ZnO}$ is $6.5 \times 10^{-6}{ }^{\circ} \mathrm{C}^{-1}$, which is lower than that of the glass substrate $\left(8 \times 10^{-6}{ }^{\circ} \mathrm{C}^{-1}\right)$. This is different from the report of residual tensile strain in ZAO thin films by Zhang et al. ${ }^{[10]}$. Although it could cause the decrease in the interplanar spacing of (002) when $\mathrm{Zn}$ atoms were replaced by $\mathrm{Al}$ atoms at their lattice sites which brought tensile stress in the films, because $\mathrm{Al}^{3+}$ has a smaller ionic radius than $\mathrm{Zn}^{2+}$. Obviously, the the prepared films rapidly cooled could not eliminate effectively compressive strain caused by crystal defects in the films.

Because the atoms of the ZAO films had higher energy and the surface mobility to settle at stable positions with the increase of $S T$ from 25 to $200{ }^{\circ} \mathrm{C}$, the compressive stress was reduced. As $S T$ was further increased from 200 to $300{ }^{\circ} \mathrm{C}$, the atoms had more energy to re-arrange themselves and recrystallize and the compressive stress was increased, showing that more grain boundaries emerged as a result of recrystallization of $\mathrm{ZnO}$ at $300^{\circ} \mathrm{C}$. The compressive stress decreased as $S T$ increased from 25 to $200{ }^{\circ} \mathrm{C}$, indicating that the intrinsic stress related to the defects in the ZAO lattice played an important role.

The crystallite size first increased and then slightly decreased with increasing $S T$. The crystallite size of the film deposited at $200{ }^{\circ} \mathrm{C}$ was obviously larger than that at 25,100 , and $300{ }^{\circ} \mathrm{C}$. At $25^{\circ} \mathrm{C}$, the ZAO film's grains grew limitely along the substrate surface. Increasing ST from 25 to $200{ }^{\circ} \mathrm{C}$ enhanced the growth of grains, but decreased with further increasing of $S T$ to $300{ }^{\circ} \mathrm{C}$, which was probably related to grain refinement by the recrystallization of $\mathrm{ZnO}$ at $300{ }^{\circ} \mathrm{C}$.

\section{Optical properties}

Fig.3 shows the optical transmittance in the wavelength range of $300-760 \mathrm{~nm}$ for ZAO films deposited at different substrate temperatures. It can be seen that the spectra had undulating profiles because of the interference originating from the reflection at the films' interfaces. The transmittance decreased rapidly at wavelengths below $400 \mathrm{~nm}$ and reached 0 at approximately $370 \mathrm{~nm}$, because the energy below wavelength of $370 \mathrm{~nm}$ was higher than the band gap of intrinsic $\mathrm{ZnO}(3.37 \mathrm{eV}$ ). Moreover, in the ultraviolet range, the absorption edge shifted towards shorter wavelengths. The average transmittance of samples deposited at $25,100,200$, and $300{ }^{\circ} \mathrm{C}$ were $90.3,89.6,90.6$, and $87.6 \%$, respectively. The lower transmittance at $300{ }^{\circ} \mathrm{C}$ was caused by grain refinement resulting from the recrystallization of $\mathrm{ZnO}$, which led to the increase in scattering, reflection, and optical absorption.

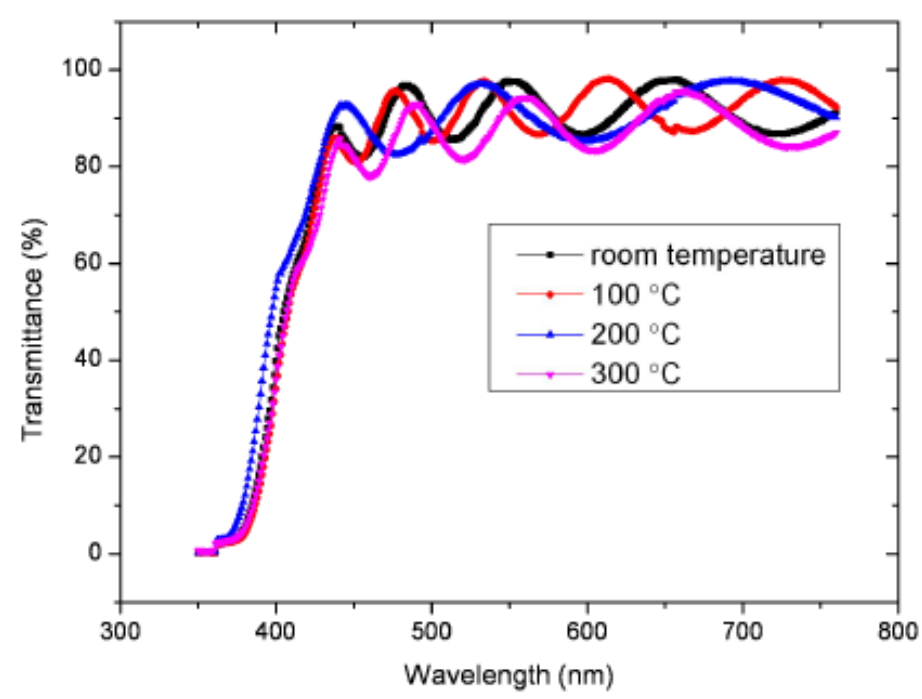

Figure 3 UV-visible light transmittance of samples 


\section{Electrical properties}

The carrier concentration, Hall mobility, and resistivity are plotted in Fig. 4 as functions of substrate temperature; their values were in the approximate ranges of $1.2-3.0 \times 10^{20} \mathrm{~cm}^{-3}, 3.0-8.0 \mathrm{~cm}^{2} \mathrm{~V}^{-1} \mathrm{~s}^{-1}$ and 9.7-2.0 $\times 10^{-4} \Omega \mathrm{cm}$, respectively. It was observed that the carrier concentration increased as $S T$ increased from 25 to $200{ }^{\circ} \mathrm{C}$, but decreased as $S T$ increased from 200 to $300{ }^{\circ} \mathrm{C}$. And the changes in resistivity were opposite. At the room temperature, there was water vapor with higer content in chamber, and it could be lonized as $\mathrm{H}$ and $\mathrm{O}$ in the plasma. The element $\mathrm{H}$ may exist as $\mathrm{H}^{+}, \mathrm{H}^{-}$and $\mathrm{H}^{0}$, but it mainly existed as $\mathrm{H}^{+}$in $\mathrm{ZnO}$ films proved by the theory and experiments ${ }^{[11,12]}$. It was certificated by many groups that the the interstitial $\mathrm{H}^{+}$was a shallow donor and contributed a lot to the n-type nature of $\mathrm{ZnO}$. Although $\mathrm{H}^{+}$had a high solubility in $\mathrm{ZnO}$ film, it was transformed into an acceptor as it was easy to form $\mathrm{H}-\mathrm{O}$ band combined with $\mathrm{O}^{2-}$, which was also the reason of higher resistivity with low substrate temperature. Furthermore, the formationof $\mathrm{H}-\mathrm{O}$ bonds also cause relaxation of the surrounding atoms and increase the stress.

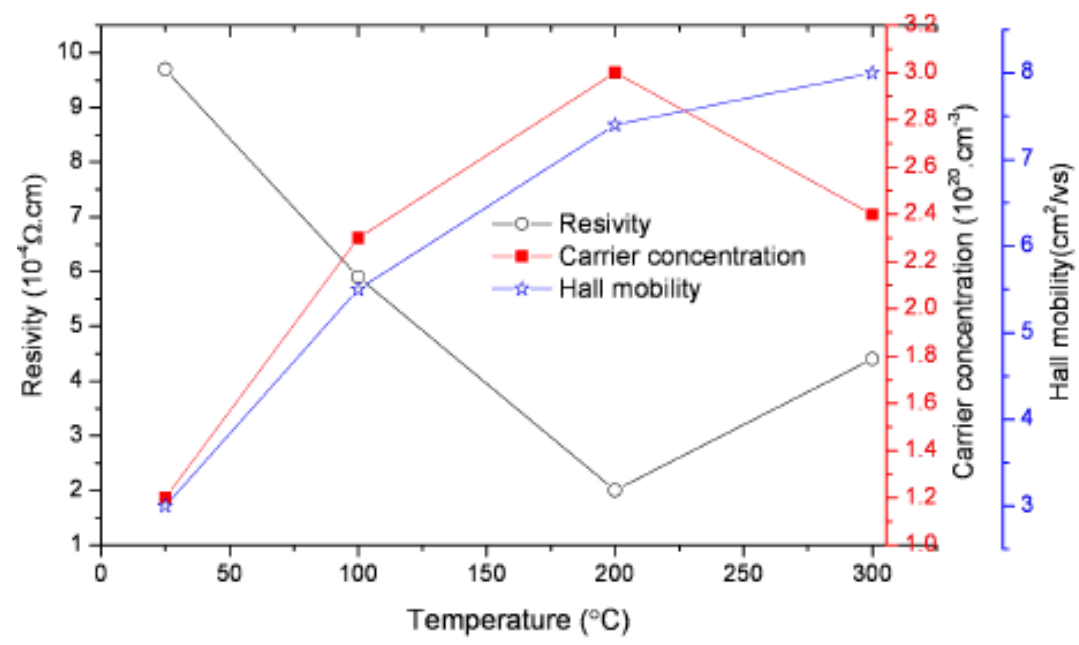

Figure 4 Resistivity,carrier concentration,and Hall mobility of the samples

On the other hand, at lower ST, more Al could be easily incorporated into the film since the $\mathrm{Al}$ sticking coefficient is inversely related to the exponential of temperature, thus increasing the number of $\mathrm{Al}$, causing the carrier concentration to increase, as shown in the measurements. It has been reported ${ }^{[13]}$ that the energy barrier for self-diffusion of intrinsic defects in $\mathrm{ZnO}$ is lowest for $\mathrm{Zn}^{2+}$ interstitials, so that the $\mathrm{Zn}$ interstitial atoms could readily diffuse through the bulk, especially along the films' grain boundaries, and evaporate from the surface. $\mathrm{Zn}$ vacancies would have been left after this process or the extinction of oxygen vacancies, which are acceptors, thereby the net carrier concentration reduced at higher temperatures $\left(S T=300{ }^{\circ} \mathrm{C}\right)$. The mobility increased with increasing substrate temperature, which could be attributed to the thermal annihilation of point defects, dislocations and stacking faults, within the grains as well as grain boundaries reduced. Smaller grain size and higer defect density would increase the probability of electron scattering, reducing the Hall mobility. The Hall mobility of the film deposited at $25{ }^{\circ} \mathrm{C}$ was low mainly because of the scattering from the grain boundaries as the grain size was smaller. This is supported by XRD results, which indicate that the film grown at $200{ }^{\circ} \mathrm{C}$ was more crystalline and the crystallinity decreased with growth temperature increased from 200 to $300{ }^{\circ} \mathrm{C}$.

\section{Conclusion}

In conclusion, the microstructure of ZAO films prepared by magnetron sputtering were effected significantly by substrate temperature, and the optical and electrical properties were dependented on the microstructure of the films. When substrate temperature increased from 25 to $200{ }^{\circ} \mathrm{C}$, the grain size of the films changed from 16.92 to $30.62 \mathrm{~nm}$, and the resistivity decreased from $9.7 \times 10^{-4}$ to $2.0 \times 10^{-4} \Omega \mathrm{cm}$. As substrate temperature increased from 200 to $300^{\circ} \mathrm{C}$, the grain size decreased to 
$17.89 \mathrm{~nm}$, and the resistivity increased to $4.2 \times 10^{-4} \Omega . \mathrm{cm}$. From XRD and SEM results of the ZAO films, it showed a crystallinity improvement at $S T=200{ }^{\circ} \mathrm{C}$. Good quality films, with resistivity that was as low as $2.0 \times 10^{-4} \Omega \mathrm{cm}$ and around $91 \%$ transmittance in the visible region, were obtained at a substrate temperature of $200^{\circ} \mathrm{C}$.

\section{Acknowledgements}

This work was financially supported by the International Science \& Technology Cooperation Program of China (No. 2013DFA51000) and the National Natural Science Foundation of China (No. 51102122). The authors also thank the Natural Science Foundation (20142BAB206008), the Department of Education (GJJ14646) and Students Innovation and Entrepreneurship Project (703304-12) of Jiangxi Province, China

\section{References}

[1] S.-M. Park, T. Ikegami, K. Ebihara, Effects of substrate temperature on the properties of Ga-doped ZnO by pulsed laser deposition, Thin Solid Films,2006, 513, 90-94.

[2] N.Y. Yuan, S.Y. Wang, C.B. Tan, X.Q. Wang, G.G. Chen, J.N. Ding, The influence of deposition temperature on growth mode, optical and mechanical properties of ZnO films prepared by the ALD method, Journal of Crystal Growth, 2013,366, 43-46.

[3] H. Zhu, H. Wang, W. Wan, S. Yu, X. Feng, Influence of oxygen and argon flow on properties of aluminum-doped zinc oxide thin films prepared by magnetron sputtering, Thin Solid Films, 2014,566, 32-37.

[4] F. Lu, C. Xu, L. Wen, Analysis on the process of ZAO films by DC magnetron reactive sputtering, Science China Technological Sciences, 2010,54, 28-32.

[5] C. Guillén, J. Herrero, Optical, electrical and structural characteristics of Al:ZnO thin films with various thicknesses deposited by DC sputtering at room temperature and annealed in air or vacuum, Vacuum, 2010,84, 924-929.

[6] R.-x. Ma, M.-k. Wang, B. Kang, Y.-g. Wang, Study on the structural, electrical and optical properties of Al-F co-doped $\mathrm{ZnO}$ thin films prepared by RF magnetron sputtering, Optoelectronics Letters, 201,7, 45-48.

[7] X.-Y. Li, H.-J. Li, Z.-J. Wang, H. Xia, Z.-Y. Xiong, J.-X. Wang, B.-C. Yang, Effect of substrate temperature on the structural and optical properties of $\mathrm{ZnO}$ and $\mathrm{Al}$-doped $\mathrm{ZnO}$ thin films prepared by dc magnetron sputtering, Optics Communications,2009, 282, 247-252.

[8] M.G. Varnamkhasti, H.R. Fallah, M. Zadsar, Effect of heat treatment on characteristics of nanocrystalline ZnO films by electron beam evaporation, Vacuum, 2012,86, 871-875.

[9] B.L. Zhu, X.H. Sun, X.Z. Zhao, F.H. Su, G.H. Li, X.G. Wu, J. Wu, R. Wu, J. Liu, The effects of substrate temperature on the structure and properties of $\mathrm{ZnO}$ films prepared by pulsed laser deposition, Vacuum, 2008,82, 495-500.

[10] Z. Zhang, C. Bao, W. Yao, S. Ma, L. Zhang, S. Hou, Influence of deposition temperature on the crystallinity of Al-doped $\mathrm{ZnO}$ thin films at glass substrates prepared by $\mathrm{RF}$ magnetron sputtering method, Superlattices and Microstructures, 2011,49, 644-653.

[11] K. Ahn, Y.S. Jeong, H.U. Lee, S.Y. Jeong, H.S. Ahn, H.S. Kim, S.G. Yoon, C.R. Cho, Physical properties of hydrogenated Al-doped $\mathrm{ZnO}$ thin layer treated by atmospheric plasma with oxygen gas, Thin Solid Films, 2010,518, 4066-4070.

[12] F.T. Kong, H.J. Tao, H.R. Gong, Interstitial hydrogen in $\mathrm{ZnO}$ and BeZnO, International Journal of Hydrogen Energy, 2013,38, 5974-5982. 
[13]J.C. Fan, K.M. Sreekanth, Z. Xie, S.L. Chang, K.V. Rao, p-Type ZnO materials: Theory, growth, properties and devices, Progress in Materials Science, 2013,58, 874-985. 